\title{
Conceptualising Consistency: Coherence, Principles, and the Practice of Human Protection
}

\author{
Noele Crossley \\ Research Associate, Oxford Department of International Development, \\ University of Oxford, Oxford, U.K. \\ noele.crossley@qeh.ox.ac.uk
}

\begin{abstract}
'Consistency' has a range of meanings in the context of human protection practice. This article conceptualises consistency - a basic premise for the legitimacy of norms, both procedurally as well as substantively. First, 'consistency' can refer to the coherence of the human protection framework. Second, consistency can refer to the degree to which protection responses adhere to international law and conform with international norms. Third, 'consistency' can mean the absence of variability and unevenness in the application of norms. I argue that consistency understood as coherence facilitates protection responses in line with international law, and, second, that a coherent protection framework encourages the even and invariable application of norms of protection by assigning responsibilities to individual protection agents. However, the international human protection regime remains incoherent: it is ambiguous and it is insufficiently integrated with other regimes and across institutions.
\end{abstract}

\section{Keywords}

coherence - consistency - responsibility - norms - human rights - human protection 


\section{Introduction}

$\operatorname{con}^{*} \operatorname{sis}^{*} \operatorname{ten}^{*} \operatorname{cy}^{1}$

2 a: agreement or harmony of parts or features to one another or a whole b: harmony of conduct or practice with past performance or stated aims

What does 'consistency' mean in the context of human protection? Consistency can refer to the adherence to principles, for example, when relevant actors suggest that 'humanitarian intervention must only be used exceptionally within tightly defined and consistently applied criteria.' ${ }^{2}$ Alternatively, consistency can refer to the degree of evenness in the provision of protection across cases, the extent to which protective agents succeed at avoiding the 'insufficient, inconsistent, or ineffective' application of these norms. ${ }^{3}$ In either case, consistency is implicitly regarded as a standard against which the legitimacy of protective responses is assessed. When states violate rules of international society in the pursuit of protection, through inaction where it is imperative, or unilateral action not sanctioned by other states, they are seen to act inconsistently. When states fail to discharge protection duties because of inaction in some cases, but not all, they are again seen to act inconsistently. The protection regime is presently constituted in such a way that consistent compliance with norms is not always congruent with consistent protection across cases. Sometimes interests align in a way that permits consistency of practice in compliance with substantive and procedural norms, but in many cases they do not. Interventions in Kosovo, Libya, or Darfur illustrate this problem - a logical trap' 4 that plagues the international human protection regime. ${ }^{5}$

The protection regime is still in its infancy and, as is the case for other emergent regimes, inconsistent practice is therefore to be expected. However, as the regime and the norms associated with it begin to consolidate,

1 Britannica Academic, 'Consistency', 2019.

2 House of Commons, 'Global Britain: The Responsibility to Protect and Humanitarian Intervention' (UK Parliament, 10 September 2018), https://publications.parliament.uk/pa/cm 201719/cmselect/cmfaff/1719/171902.htm.

3 'UK Government Strategy on the Protection of Civilians in Armed Conflict' (Foreign \& Commonwealth Office, 7 December 2011), https://www.gov.uk/government/uploads/system/ uploads/attachment_data/file/32950/ukstrategy-protect-cvilians-arms-conflict.pdf.

4 Roland Paris, "The "Responsibility to Protect" and the Structural Problems of Preventive Humanitarian Intervention', International Peacekeeping, 21(5): 569-603 (2014).

5 Alex J. Bellamy, 'The Humanisation of Security? Towards an International Human Protection Regime', European Journal of International Security, 1(1): 112-33 (February 2016), https://doi .org/10.1017/eis.2015.5. 
more consistency, in future, in the application of norms of protection might be expected. The regime encompasses norms and institutions associated with international human rights law, international humanitarian law, and international criminal law. 'Human protection' was coined in $2008 .{ }^{6}$ The concept refers to the role of international actors in protecting civilian populations at risk of harm through direct violence as a consequence of conflict, as well as from the indirect consequences of conflict, such as displacement and a lack of access to food, shelter, and medication. A range of measures is at the disposal of states and other actors in discharging protection duties, including preventive diplomacy, sanctions, the provision of humanitarian relief, or peacekeeping. ${ }^{7}$ The concept thus departs from a narrower understanding conflating protection with military intervention designed to prevent atrocities and mitigate humanitarian suffering, deflecting some of the critique levelled against similar concepts, including 'humanitarian intervention', and the 'responsibility to protect. ${ }^{8}$ However, policy labels are less salient in the discussion that follows below. What matters here is how the concept of 'consistency' relates to practices of protection and the discourse.

Despite the fact that 'consistency' is inscribed into our moral grammar as a precondition for legitimacy and justice (indeed, it is so obvious that legal philosophy hardly engages with the concept), the concept has received limited attention in the literature. ${ }^{9}$ Scholars, policymakers, and practitioners alike, while lamenting the absence of consistency, have had little to say about the meaning of consistency, and how it could be measured. It is difficult to ascertain what, precisely, the consistent invocation and application of protection norms actually entails, given that 'consistency' means different things in different contexts. How can 'consistency' be conceptualised, and what makes a consistent protection regime?

A normative argument in favour of consistency underpins this contribution, but does not define its purpose. The assumption upon which the argument developed here is grounded is that, while some arguments in favour of

6 UN Secretary-General, 'Cyril Foster Lecture at Oxford University: "Human Protection and the 21st Century United Nations"', United Nations, 2 February 2011, https://www.un.org.

7 UN Secretary-General, Implementing the Responsibility to Protect, A/63/677, 12 January 2009.

8 Noele Crossley, 'Is R2P Still Controversial? Continuity and Change in the Debate on Humanitarian Intervention', Cambridge Review of International Affairs, 31(5): 415-36 (2018).

9 Martin Binder, The United Nations and the Politics of Selective Humanitarian Intervention (Cham, Switzerland: Springer Nature for Palgrave Macmillan, 2017); Andrea L. Everett, $\mathrm{Hu}$ manitarian Hypocrisy: Civilian Protection and the Design of Peace Operations (Cornell: Cornell University Press, 2018). 
inconsistency are certainly compelling, ${ }^{10}$ there are also some good arguments in favour of coherence and consistency. ${ }^{11}$ While this contribution will not seek to address this debate, the argument will therefore be based on the premise that consistency in the application of norms of protection, as well as consistency of protective responses with the law and ethical principles, are both desirable features of protection practice. This assumption, the reader should however note, is not one that is universally accepted, and the reader may wish to consult some instructive recent works on pragmatist ethics for a useful summary of the central arguments made by thinkers of a pragmatist inclination. ${ }^{12}$ In what follows below I will argue that, while some of these arguments are pertinent, inconsistency is not inconsequential: norm consolidation occurs where habitual practice can be observed - a sociological fact discounted by pragmatists. $^{13}$

The article proceeds in three parts. Each part addresses a separate dimension of consistency: coherence, compliance, and invariability. ${ }^{14}$ First, 'consistency' refers to 'coherence': 'agreement or harmony of parts or features to one another or a whole'. ${ }^{15}$ Second, 'consistency' refers to 'harmony of conduct', ${ }^{16}$ in

10 Chris Brown, 'Selective Humanitarianism: In Defence of Inconsistency', in Deen Chatterjee and Don Scheid (eds.), Ethics and Foreign Intervention (Cambridge: Cambridge University Press, 2003), pp. 31-50.

11 Noele Crossley, 'Consistency, Protection, Responsibility: Revisiting the Debate on Selective Humanitarianism', Global Governance 26: 1-27 (2020); Philip Cunliffe (ed.), Critical Perspectives on the Responsibility to Protect: Interrogating Theory and Practice (London: Taylor \& Francis Group, 2011); David Chandler, 'Understanding the Gap Between the Promise and Reality of the Responsibility to Protect', in Critical Perspectives on the Responsibility to Protect: Interrogating Theory and Practice (Taylor \& Francis Group, 2011), pp. 19-34.

12 Daniel Bray, 'Pragmatic Ethics and the Will to Believe in Cosmopolitanism', International Theory, 5(3): 446-76 (2013); Jason Ralph, 'What Should Be Done? Pragmatic Constructivist Ethics and the Responsibility to Protect', International Organization, 72(1): 173-203 (2018).

13 Siegfried Schieder, 'Pragmatism as a Path towards a Discursive and Open Theory of International Law', European Journal of International Law, 11(3): 663-98 (2000).

14 Nicholas Wheeler argues that a distinction needs to be made between 'consistency' and 'coherence': 'The latter depends upon a framework that starts from the premise that like cases must be treated alike, but acknowledges that this does not mean that every case can be treated the same.' See Nicholas Wheeler, Saving Strangers: Humanitarian Intervention in International Society (Oxford: Oxford University Press, 2003), p. 305. NB: in the framework suggested here, 'coherence' means the absence of internal contradictions, rather than the premise that like cases ought to be treated alike. Wheeler also distinguishes between selectivity for prudential reasons, and selectivity for prudential reasons.

15 Britannica Academic, 'Consistency', 2 a.

16 Britannica Academic, $2 \mathrm{~b}$. 
other words, compliance with international law and conformity with emerging and consolidating norms associated with the protection regime; and, third, 'consistency' refers to 'harmony of practice':17 the invariability in the delivery of protection to populations in need, as well as the absence of selectivity (meaning that all crises are addressed), as well as invariability in the degree of tenacity displayed by international actors when responding to protection crises (but not necessarily uniform responses, given that every crisis is different and international actors can draw on a repertoire of coercive and non-coercive measures in responding to protection crises).

'Normative coherence requires compatibility among a cluster of cognate norms', Ramesh Thakur suggests, whereas 'inconsistency refers to unevenness in the application of any one particular norm. ${ }^{18}$ Coherence, as will be illustrated below, is a precondition for consistency as conformity, as well as for consistency as invariability. Coherence is a precondition for both principled protection practices, as well as tenacious and invariable protection practice. Without a coherent framework, and without coherent principles, rules, and norms, it is difficult for protection agents to meet protection responsibilities in a principled way; without clearly defined duties and responsibilities, collective action problems and lack of coordination will continue to stymie the provision of protection to all populations in need. However, the international human protection regime that provides the normative and institutional structure for protecting civilians remains incoherent: it is ambiguous, internally conflicted, and insufficiently integrated with other regimes. It also continues to be insufficiently institutionalised. The specific consequences of these issues will be outlined in further detail below.

The central argument of this contribution is that coherence is a precondition for both consistency understood as conformity, as well as for consistency understood as invariability. With regard to consistency understood as conformity, the failure to act consistently - understood as the compliance with international norms - delegitimises the nascent protection regime and associated norms and, importantly, undermines trust in the regime which, in turn, may corrode the fragile consensus that now exists, ${ }^{19}$ or impede the continued consolidation of norms associated with the regime by challenging their legitimacy. 'Legitimacy' can refer to either normative or sociological legitimacy (a norm's

17 Britannica Academic, 2 b.

18 Emphasis in the original. See Ramesh Thakur, 'Developing Countries and the InterventionSovereignty Debate', in Richard M. Price and Mark W. Zacher (eds.), The United Nations and Global Security (New York: Palgrave Macmillan, 2004), p. 197.

19 Jennifer Welsh, 'Norm Contestation and the Responsibility to Protect', Global Responsibility to Protect, 5(4): 365-96 (2013). 
inherent validity, or its perceived validity). ${ }^{20}$ Sociological legitimacy assumes a rule may be perceived to be valid even when it is followed by members of a society owing to its status as a rule, rather than because of its perceived intrinsic worth. When states violate the rules of the human protection regime it discredits the regime's sociological legitimacy. With regard to consistency understood as invariability, inconsistent protection - understood as selectivity, or varying degrees of tenacity of protection responses - means that not all civilians in need of protection are protected. This is obviously unsatisfactory in consequentialist terms, but inconsistency of practice also violates fundamental norms of equity and distributive justice.

Consistency as coherence, in this context, means the absence of norm conflict. Through the prism of political theory, Aristotle provides a useful description of the meaning of the term in this interpretation. 'Consistency' is a quality of a concept that is sound, with few internal contradictions, or none. ${ }^{21}$ 'Coherence' may be a useful synonym for consistency thus understood. 'Coherence' is 'a state or situation in which all the parts or ideas fit together well so that they form a united whole, ${ }^{22}$ suggesting a 'systematic or logical connection' between constituent parts, and the 'integration of diverse elements, relationships, or values. ${ }^{23}$

The emerging human protection regime has done much to improve consistency understood as coherence. The discursive shift from 'humanitarian intervention', associated with armed intervention, to a 'responsibility to protect', incorporating a repertoire of measures to halt or prevent atrocity crimes, has aided the reconciliation of international norms relating to human rights enforcement on the one hand, and international norms pertaining to the sanctity of state sovereignty and the inviolability of territorial integrity on the other. It has done so, first, through the 'sovereignty as responsibility' formula first outlined by Francis Deng in the context of the protection of internally displaced

$20 \quad$ Allen Buchanan and Robert O. Keohane, 'The Legitimacy of Global Governance Institutions', Ethics \& International Affairs, 20(4): 405-37 (2006).

21 Aristotle, Metaphysics, Volume 1, trans. Hugh Tredennick (Cambridge MA: Harvard University Press, 1933).

22 Collins English Dictionary, 'Coherence Definition and Meaning', https://www.collinsdic tionary.com/dictionary/english/coherence, accessed 6 August 2019.

23 Merriam-Webster, 'Definition of “Coherence"', https://www.merriam-webster.com/dic tionary/coherence, accessed 6 August 2019. 
people (IDPs), ${ }^{24}$ that made sovereignty contingent upon protection, without weakening its normative significance; second, by narrowing its scope to atrocity prevention and, effectively, raising the threshold for coercive intervention; and, third, by conceptualising prevention and response as entailing a range of measures, both coercive and non-coercive, including, but not limited to, armed force as a last resort. The new framework, arguably, has been successful at reframing the terms of the debate, but that is not to say that the regime does not still abound in inconsistencies. Furthermore, the absence, as yet, of an explicit international endorsement, in legally binding terms, by states, of a responsibility to protect, and a wider cluster of protection norms, with reference to clearly assigned duties, suggests the human protection regime is still emerging. Inconsistency is therefore to be expected, until the behaviour of states and other protection agents begins to converge around new expectations and this is reflected in their practice.

At present, the emerging international protection regime lacks coherence in three respects. First, the regime remains internally conflicted in that the conditionality imposed on state sovereignty through the 'sovereignty as responsibility' formula lacks a clear articulation of parameters and triggering thresholds further to which the principle of state sovereignty must yield to the responsibility to protect. ${ }^{25}$ With regard to atrocity prevention, the World Summit Outcome Document (WSOD), adopted by the United Nations (UN) General Assembly in September 2005, endorses collective action through the UN Security Council 'should peaceful means be inadequate and national authorities manifestly fail to protect their populations from genocide, war crimes, ethnic cleansing and crimes against humanity.' ${ }^{26}$ However, the 'manifestly failing' threshold is ambiguous, and unsurprisingly therefore, its application in the international

24 Francis M. Deng, Sadikiel Kimaro, Terrence Lyons, Donald Rothchild, and I. William Zartman, Sovereignty as Responsibility (Washington DC: Brookings Institution Press, 1996); Francis M. Deng, 'From Sovereignty as Responsibility to the Responsibility to Protect', Global Responsibility to Protect, 2(4):353-70 (2010), p. 353 .

25 Melissa Labonte points out that international practice has been inconsistent. See Melissa T. Labonte, 'Whose Responsibility to Protect? The Implications of Double Manifest Failure for Civilian Protection', The International Journal of Human Rights, 16(7): 982-1002 (2012). With reference to the case of Syria, Adrian Gallagher develops a framework for assessing whether the 'manifestly failing' threshold referred to in the World Summit Outcome Document - given its status as a resolution of the General Assembly, the best indication yet of an international consensus on basic principles of human protection responsibilities - has been met. See Adrian Gallagher, 'Syria and the Indicators of a "Manifest Failing"', The International Journal of Human Rights, 18(1): 1-19 (2014).

26 '2005 World Summit Outcome', UNGA Res. 6o/1, 16 September 2005. 
discourse on protection has been inconsistent. ${ }^{27}$ The report of the International Commission on Intervention and State Sovereignty (ICISs) had suggested an 'unable or unwilling' threshold for armed intervention. 'Military intervention for human protection purposes is justified', the report suggests, in order to halt or avert 'large scale loss of life ... or large scale "ethnic cleansing,,... ${ }^{28}$ The report provides further guidance, listing several situations that fall under either of these conditions: actions defined by the Genocide Convention; the occurrence of large scale loss of life, whether intended or not; any form of 'ethnic cleansing'; crimes against humanity and violation of the laws of war; state collapse and civil war; and natural disasters, where relevant authorities cannot cope and fail to call for assistance. ${ }^{29}$ Furthermore, the Commission outlined situations that do not justify military intervention for human protection purposes: human rights violations 'falling short of outright killing or ethnic cleansing'; unconstitutional changes of government (where a change in government does not activate either of the two threshold criteria); and, third, a state's rescue of its own nationals on foreign territory. By defining just cause threshold criteria as well as determining situations that did not fall under the principle as outlined by the Commission, the report was relatively specific when compared to the wsoD endorsed by states several years later. However, unlike the World Summit Outcome Document, the ICISs report, as a publication of an independent commission, is prescriptive, rather than instructive in a political sense, and the WsoD, given its status as a UN General Assembly resolution, is more reflective of the scope and substance of international consensus on basic criteria with regard to protective intervention. In any case, the fissure between human rights protection on the one hand, and respect for state sovereignty on the other continues to permeate the protection regime - in theory, as well as in practice where, on a day-to-day basis, protection agents must negotiate the terms under which access to civilians is granted.

Second, a lack of specification continues to curtail the ability of international actors to apply norms of protection in a consistent way. It prevents the equal application of norms of protection to all individuals and groups who, according to the law, have a right to protection. Not only is the regime not underpinned by a corpus of international law, and attendant institutions, that unequivocally determine just cause criteria and triggering thresholds, but it

27 Adrian Gallagher, 'What Constitutes a "Manifest Failing"? Ambiguous and Inconsistent Terminology and the Responsibility to Protect', International Relations, 28(4): 428-44 (2014).

28 International Commission on Intervention and State Sovereignty (ICISs), The Responsibility to Protect (Ottawa: IDRC, 2001), p. 32.

ibid., p. 33 . 
also fails to outline what types of responses are appropriate in which situations, as well as to determine specific protection responsibilities for specific actors. The 2009 report of the Secretary-General, Implementing the Responsibility to Protect, ${ }^{30}$ provides some further guidance, but again does not constitute a legally binding document. The context in which a right to protection may be invoked is specific, particular to each case. So far, international actors have not yet been successful at articulating general principles that outline, with sufficient clarity, the general conditions under which a right to protection emerges. Complex humanitarian emergencies typically result from specific contexts. A duty to respond, in the discharge of protection responsibilities, may thus arise at different situations at different points in the conflict cycle, and is contingent upon the recognition, by international actors, of the situation as a 'case' in which protective intervention is appropriate. However, not all cases that may qualify are recognised as such - and when they are, the absence of clearly defined conditions, or triggering thresholds and criteria, means that agents tasked with protection may refer to other norms in justifying inaction. In effect, the ambiguity of the regime provides an opportunity for double standards. While some vulnerable populations receive protection, others do not.

Furthermore, protective measures differ. A protection repertoire was outlined in the Implementing the Responsibility to Protect report. ${ }^{31}$ However, different agents operate according to different operating procedures, with distinct guidelines. Both in terms of policy, as well as in practical terms, these may contradict each other. For example, the UN's conflict management institutions parallel those within regional arrangements, such as the Association of Southeast Asian Nations (ASEAN), the Organisation for Security and Cooperation in Europe (OSCE), the African Union (AU), and the Arab League. The international and regional levels may complement each other; for example, through capacity-building, knowledge exchange, as well as ad-hoc support in the form of provision of good offices and material support during times of crisis. However, international and regional responses can interfere with each other, with potentially adverse effects, when they are not well-coordinated or when institutions compete for influence. An example here is the poorly coordinated collective response to the crisis in Libya, where the AU's attempt to establish a mediation process with the aim of bringing about a peaceful resolution of the conflict was curtailed by NATO's military campaign, authorised by the UN

$30 \quad$ UN Secretary-General, Implementing the Responsibility to Protect.

$31 \quad$ Ibid. 
Security Council in March 2011. ${ }^{32}$ It is yet unclear whether a mechanism of subsidiarity might emerge to guide expectations in this field, and little attention has been paid to discussing the advantages, or disadvantages, of assigning responsibility in this way.

However, the wide range of conflict situations, and the complexity of response mechanisms, may not explain the continued absence of clear guidelines. States have resisted further clarification. Conflicting interests mean that states with the means to respond typically respond inconsistently, ${ }^{33}$ and in general, states with the capacity for decisive response have been more reluctant to commit to a principle of consistent intervention, as was reflected in the United States' cautious justifications for intervention in Libya. ${ }^{34}$ Ambiguity provides protection agents with liberty to respond in a way best suited to realising effective protection, and allows these agents to respond where it is also most in their interest to do so, encouraging robust responses. A problem arises when no agent feels compelled to provide protection; in this case, some vulnerable groups will be left without protection.

A further obstacle is insufficient institutionalisation, making it difficult for protection agents to apply norms consistently. Norms are infused with life through practice, and, consequently, begin to take shape through repeated interaction among relevant actors. Norms consolidate where practices are institutionalised and actors build trust and develop expectations about appropriate responses to specific situations, as can be seen in other issue areas, including trade, the environment, or arms proliferation. ${ }^{35}$ In the realm of human rights protection, similarly, an international regime defines expectations, and structures collective action. ${ }^{36}$ The institutionalisation of norms of protection suggests the growing influence of the emerging protection regime. The formalisation of human protection practice reduces ambiguity, and in doing so

32 Security Council Resolution 1973 authorised all necessary measures to protect civilians. S/RES/1973, 17 March 2011.

33 Aidan Hehir, 'The Permanence of Inconsistency: Libya, the Security Council, and the Responsibility to Protect', International Security, 38(1): 137-59 (2013).

34 Simon Chesterman, "Leading from Behind": The Responsibility to Protect, the Obama Doctrine, and Humanitarian Intervention after Libya', Ethics \& International Affairs, 25(3): 279-85 (2011).

35 Waheguru Pal Singh Sidhu, 'The Nuclear Disarmament and Non-Proliferation Regime' in Paul D. Williams (ed.), Security Studies: An Introduction (Abingdon, Oxon: Routledge, 2018); Farhana Yamin and Joanna Depledge, The International Climate Change Regime: A Guide to Rules, Institutions and Procedures (Cambridge: Cambridge University Press, 2004).

36 Jack Donnelly, 'International Human Rights: A Regime Analysis', International Organization, 40(3): 599-642 (1986). 
improves the perceived legitimacy of protection practice. A framework assigning roles and responsibilities helps, further, to shape expectations and, through habitual practice, produces trust in the protection regime and responsible actors. Social institutions 'depend on trust for their functioning ... a frequent lament of the abused and of the betrayed is that they have lost the ability to trust' and without this ability, an agent cannot enjoy 'the benefits of engagement in cooperative activity' ${ }^{37} \mathrm{~A}$ capacity for consistency is thus critical, as is the need for accepting the risk this involves. Indeed, experimental research has found consistency of behaviour to be the most important factor in determining cognitive-based trust. ${ }^{38}$ It stands to reason, therefore, that consistent adherence to norms of protection, as well the consistent application of these norms, as will be discussed below, allows protection agents and beneficiaries to invest resources in the institutions that embody the regime, and to co-ordinate their responses through these institutions.

Consistency understood as compliance and conformity means that international actors respond to conflict and complex humanitarian emergencies in a way that is in accordance with accepted norms and principles, both substantive and procedural. Effectively, it is about a protection agent's adherence to norms of protection in respect to a case. The substance of the principle - for example, multilateral implementation of responses, or responses driven by humanitarian dedication - is not the object of concern here. Consistency as compliance and conformity refers to the extent to which an agent's case-specific response complies with rules, norms, and principles (irrespective of whether these are customarily followed by other actors, i.e., the extent to which they constitute general practice or a norm). 'Agent' can be used in the plural here, as when pertaining to the response of a coalition of states or states acting through the UN Security Council. While determining the lawfulness of international protective action entailing the use of armed force is a relatively simple task - in the absence of a Security Council mandate, or authorisation through a Uniting for Peace General Assembly resolution, any use of force not justified with reference to Article $5^{1}$ of the UN Charter is impermissible - determining

37 Jason D'cruz, 'Trust, Trustworthiness, and the Moral Consequence of Consistency', Journal of the American Philosophical Association, 1(3): 467-84 (2015), p. 468.

38 Paul Dunn, 'The Importance of Consistency in Establishing Cognitive-Based Trust: A Laboratory Experiment', Teaching Business Ethics, 4(3): 285-306 (2000). 
the conformity of international responses with developing human protection norms, which are less tangible given that they are not codified in legally binding texts, is more difficult.

Furthermore, even where legal obligations are codified within treaties, their interpretation is subject to change. For example, the recognition that human rights violations could constitute a 'threat to the peace', in the context of Iraq's repression of its Kurdish and Shiite populations in Security Council Resolution 688 of April 1991, exemplifies a dramatic departure from traditional interpretations of absolute interpretations of state sovereignty. Several years later, these competing demands on international actors came to a head in the context of the crisis in Kosovo, which plainly demonstrated the contradictions. ${ }^{39}$ The responsibility to protect principle attempted to reconcile state sovereignty with the human rights imperative of preventing harm to civilians, devising the 'sovereignty as responsibility' formula to mediate between the two principles. ${ }^{40}$

The main source of international law, aside from treaties - customary international law - is state practice, which includes codification in domestic law, and opinio juris. The UN Charter lacks coherence in that it refers to both human rights as well as the inviolability of state sovereignty, without, however, clarifying the circumstances under which one cedes to the other, introducing ambiguity. ${ }^{41}$ Reconciling the Charter with regional frameworks complicates the implementation of protective action further. Legal scholars have yet to examine the implications of regional frameworks and the relationship of their constitutive acts with traditional sources of international law, including the Charter. Some works have engaged with these issues, ${ }^{42}$ but on the whole, this is an emerging field and arguments about procedures for determining jurisdiction - for example, subsidiarity, as outlined above - have not yet been discussed extensively. Consistent application of norms to individual cases is complicated further by the existence of distinct, and potentially contradictory, bodies of law. Principal sources of international law pertaining to the protection regime are the UN Charter, regional frameworks, international human

39 On the controversy over Kosovo, see Jonathan I. Charney, 'Anticipatory Humanitarian Intervention in Kosovo', American Journal of International Law, 93(4): 834-41 (1999), and Louis Henkin, 'Kosovo and the Law of "Humanitarian Intervention"', American Journal of International Law, 93(4): 824-28 (1999).

$40 \quad$ ICIss, The Responsibility to Protect.

41 W. Michael Reisman, 'Sovereignty and Human Rights in Contemporary International Law', American Journal of International Law, 84(4): 866-76 (1990), p. 876.

42 Harmen van der Wilt, 'Complementary Jurisdiction (Article 46H)', in Gerhard Werle and Moritz Vormbaum (eds.), The African Criminal Court: A Commentary on the Malabo Protocol, International Criminal Justice Series (The Hague: T.M.C. Asser Press, 2017), pp. 187-202. 
rights law (IHRL), international humanitarian law (IHL), and international criminal law (ICL). International courts, within the legal paradigm, and international actors including states and regional organisations, must determine which actor - and therefore which body of law - applies. For IHRL, which is always applicable, and IHL, which applies during armed conflict, lex specialis or, alternatively, harmonisation theory is used to determine which body of law applies.

These contradictions - and, consequently, competing claims to responsibilitycomplicate the implementation of protective measures. In juridical terms, jurisdictions overlap. In political terms, responsibilities are not assigned sufficiently clearly, and duties are not spelt out - international actors operate in an environment in which a protection regime is emerging, but legal provisions still lack robust enforcement mechanisms. In the absence of binding law and robust institutions, international actors have been left to their own devices to coordinate responses in individual cases. In many cases, actors with the means but not necessarily the authority to act are faced with numerous dilemmas. ${ }^{43}$ Nevertheless, claims to responsibility, given the absence of mechanisms for allocating responsibility comparable to those at the domestic level, are almost certain to accompany protection responses. Similarly, different actors will have differing opinions about appropriate measures in different crises. For example, while the UN and NATO preferred a swift and robust response in the case of Libya, in line with pillar three of the responsibility to protect principle ${ }^{44}$ - which includes armed intervention as a last resort - the African Union preferred mediation and a political settlement. Interorganisational disputes of this kind are commonplace - recent examples include Zimbabwe, Madagascar, and Cote D'Ivoire. ${ }^{45}$ While the AU advocates subsidiarity to the UN, the UN prefers a case-by-case approach in determining responsibility. ${ }^{46}$ This lack of coherence interferes with the ability of protection agents to respond in line with procedural and substantive principles.

Reducing the incoherence of the international protection regime may be a first step towards promoting consistency - understood as principles-guided

43 See, for example, James Pattison, 'Whose Responsibility to Protect? The Duties of Humanitarian Intervention', Journal of Military Ethics, 7(4): 262-83 (2008), and H. M. Roff, 'Response to Pattison: Whose Responsibility to Protect?', Journal of Military Ethics, 8(1): 79-85 (2009).

44 UN Secretary-General, Implementing the Responsibility to Protect.

45 Laurie Nathan, 'How to Manage Interorganizational Disputes over Mediation in Africa', Global Governance: A Review of Multilateralism and International Organizations, 23(2): 151-62 (2017).

46 ibid., p. 161. 
action - of international responses to human protection crises. Efforts to forge consensus in the policy domain may help to clarify international law and influence state practice. Recent efforts have been devoted to articulating the relationship, relative weight, and precedence of conflicting norms in practice. The 'Responsibility while Protecting' (RWP) initiative championed by Brazil, ${ }^{47}$ which aimed to develop guidelines for the conduct of armed forces during protection interventions, is an example of an initiative intended to bring greater transparency, and reduce the ambiguity and incoherence, of the present normative architecture. Another example is the 'Right to Assist' proposal, discussing the third-party assistance for non-violent resistance movements and the conditions under which it may be permissible. ${ }^{48}$ While RWP has had limited success, and the reception of the Right to Assist (RtoA) among policymakers remains to be seen, both initiatives are good examples of ways in which policyoriented research can help generate fruitful debate about the principles that ought to guide international practice.

\section{4}

\section{Consistency as Evenness and Invariability}

While consistency as compliance and conformity relates to the way in which protection is implemented in response to specific cases - whether actors respond to the case in line with procedural or substantive principles and rules consistency as evenness and invariability refers to the extent to which actors apply norms of protection consistently across cases. Like cases ought to be treated alike, but at present, like cases are not treated alike, and the protection regime is characterised by protection gaps. Protection gaps may result from gaps between expectations and capabilities, ${ }^{49}$ 'but may also be understood as a consequence of particular conceptualisations of protection responsibility. 50 The protection of civilians (POC) terminology used in the context of UN peacekeeping, and the narrower concept of the Responsibility to Protect $\left(\mathrm{R}_{2} \mathrm{P}\right)$ as outlined in the WSOD, relating to atrocity prevention, cannot be used to invoke

\footnotetext{
47 Marcos Tourinho, Oliver Stuenkel, and Sarah Brockmeier, "Responsibility While Protecting": Reforming R2P Implementation', Global Society, 30(1): 134-50 (2016).

48 Peter Ackerman and Hardy Merriman, Preventing Mass Atrocities: From a Responsibility to Protect (RtoP) to a Right to Assist (RtoA) Campaigns of Civil Resistance, ICNC Special Report Series vol. 3 (Washington DC: International Center on Nonviolent Conflict, May 2019).

49 Bellamy, 'The Humanisation of Security?'.

5o Ramesh Thakur, 'Protection Gaps for Civilian Victims of Political Violence', South African Journal of International Affairs, 20(3): 321-38 (2013).
} 
protection responsibility in the context of other situations that imperil the human security of individuals, including inter-state war, natural disasters, or the domestic discrimination of minority groups. The war in Iraq, the humanitarian crisis in the aftermath of Cyclone Nargis in Myanmar, or the systematic discrimination of Roma populations in Europe, serve as examples. Protection gaps also arise when protective agents, individually or collectively, fail to conjure the necessary political will to respond; where collective apathy is the result not of prudential considerations, but the absence of material incentives or prohibitive diplomatic and geostrategic costs.

This can result in a charge of hypocrisy when protection agents endorse human protection norms but fail to uphold their protection responsibilities across cases. Most states, including states with relatively greater financial, diplomatic, and military capabilities to implement protective measures, have endorsed the responsibility to protect principle and are committed to human protection norms. ${ }^{51}$ Many other actors, including humanitarian agencies and civil society actors, endorse the responsibilities associated with the protection regime. Nevertheless, James Pattison suggests that acting hypocritically is still better than inaction, because even a hypocritical allegation points to a violation, and may also serve to reinforce norms in the long run. ${ }^{22}$ However, there is a trade-off: while ethical pragmatism may be acceptable in the short term (in that human rights abuses are flagged and protection may be provided by hypocritical protectors, or protectors applying double standards), the instrumental use of protection, rather than the principled use, means that protection cannot be guaranteed and impedes the building of trust in the regime. '[T]he credibility, authority and hence effectiveness of the United Nations in advancing the principles relating to the responsibility to protect depend, in large part,' the UN report on implementing the responsibility to protect suggests, 'on the consistency with which they are applied. ${ }^{53}$

In any case, protection is not even, and the robustness and tenacity of collective responses continues to vary from case to case. While some responses

$5^{1} \quad$ Evidenced by supportive statements in General Assembly deliberations. Summaries are available at http://www.globalr2p.org/. The most recent summary is available at Global Centre for the Responsibility to Protect, 'Summary of the UN General Assembly Plenary Meeting on the Responsibility to Protect', July 2019, http://www.globalr2p.org/. For a detailed description of the reach and influence of informal groups in the UN system, see Alex J. Bellamy, 'Negotiating the Responsibility to Protect in the UN System: The Roles of Formal and Informal Groups', The Hague Journal of Diplomacy, 12(2-3): 197-220 (2017).

52 James Pattison, The Alternatives to War: From Sanctions to Nonviolence (Oxford: Oxford University Press, 2018), pp. 103-6.

UN Secretary-General, Implementing the Responsibility to Protect, p. 27. 
are decisive (where measures are proportionate to the scale of the problem) and robust (where appropriate measures are chosen, contingent upon the nature of the conflict), others are not. Despite the consolidation of protection norms at the international level, international actors continue to struggle to provide effective protection for civilian populations in Syria, Myanmar, Venezuela, and Yemen. Charges of inconsistency take various forms: 'double standards', 'selectivity', 'duplicity/ulterior/mixed motives', or inconsistency in terms of variation in outcomes.

Incoherence results in ambiguity, which may make protective action vulnerable to the charge of double standards. Selective responses may be structurally imposed and may even be unwanted on the part of the protective agent - for example, when prudential concerns prevent responses. In some circumstances, protective agents may be prepared to make sacrifices when humanitarian considerations align with other interests. In the context of the debate on military intervention by states justified on humanitarian grounds the consensus has been that because states cannot intervene everywhere, all the time, humanitarian concerns ought to be the primary, but not necessarily - or even preferably - the sole justification for intervention, and consequentialist arguments have dominated the debate. ${ }^{54}$ For example, Nicholas Wheeler suggests motives do not matter at all, so long as outcomes are positive, ${ }^{55}$ citing the cases of India's intervention in East Pakistan in the context of the Bangladesh War of 1971 (which India justified on the grounds of preventing Bengali refugees flows into India, not on grounds of protecting populations in East Pakistan from mass atrocities); Vietnam's intervention in Cambodia in 1979; and Tanzania's overthrow of the Idi Amin regime in Uganda, justified on grounds of self-defence, again, not on humanitarian grounds. ${ }^{56}$

However, motives may shape intent and as such could be regarded as significant in assessing the legitimacy of armed interventions justified on humanitarian grounds, ${ }^{57}$ and indeed, there is empirical evidence to suggest that in other domains, motives do influence outcomes. ${ }^{58}$ In other words, the scope and form of protective action and humanitarian relief may well

54 For a detailed discussion see James Pattison, Humanitarian Intervention and the Responsibility to Protect: Who Should Intervene? (Oxford: Oxford University Press, 2010), pp. 159-61.

55 Wheeler, Saving Strangers, pp. 37-38.

56 For detailed case studies, see Wheeler, Saving Strangers.

57 Alex J. Bellamy, 'Motives, Outcomes, Intent and the Legitimacy of Humanitarian Intervention', Journal of Military Ethics, 3(3): 216-32 (2004).

58 Christopher Kilby and Axel Dreher, 'The Impact of Aid on Growth Revisited: Do Donor Motives Matter?', Economics Letters, 107(3): 338-40 (2010). 
be contingent upon motive. ${ }^{59}$ While the pursuit of strategic or other interests may, on the one hand, make protective action more likely, it may also, on the other hand, produce inconsistency in the sense that humanitarian outcomes are better if humanitarian motives drive actions. This creates a dilemma: the protection regime relies on voluntary action by individual agents, yet self-interested responses may lead to poorer humanitarian outcomes. Roland Paris refers to this as 'the simultaneous necessity and preclusion of self-interest'.60

Furthermore, it is necessary to distinguish between selectivity on the grounds of capacity/remit, and selectivity resulting from other considerations; for example, politically motivated choices. Eric Heinze suggests one needs to distinguish selectivity resulting from scarce resources from politically motivated selectivity - whereas the former may be justifiable on pragmatic grounds if a priori declaration of remit is provided, selectivity resulting from discrimination on extraneous grounds is not. ${ }^{61}$ Selectivity undermines the legitimacy of an agent, Heinze suggests, only where it results from political bias - not if it is the consequence of a previously communicated selection of issues based on predetermined criteria (for example, regional or thematic focus); a problem arises when the behaviour of the protection agent is such that it suggests bias that cannot be explained on these grounds. The logic can be applied to selectivity with regard to human protection: selective protection responses may be legitimate if they can be explained by an actor's remit in terms of responsibility; however, where an actor fails to discharge protection responsibilities unrelated to their mandate - on extraneous grounds - selectivity, or the absence of invariable protection practice, may undermines a protective agent's perceived legitimacy. However, from a consequentialist perspective, this still raises questions about coordination and universal coverage - in a global self-help system, the provision of protection remains discretionary.

Nevertheless, in terms of outcomes, there is empirical evidence to suggest that the emergence of an international human protection regime has reduced the frequency and lethality of mass atrocities. ${ }^{62}$ Although the robustness of

59 Noele Crossley and Christina Qiu, 'Neoconstructivism and Quantifying International Protection Norms: A New Research Agenda' (unpublished manuscript, 2020).

6o Paris, 'The "Responsibility to Protect" and the Structural Problems of Preventive Humanitarian Intervention'.

61 The argument is made with regard to even-handedness in the invocation of human rights. Eric Heinze, 'Even-Handedness and the Politics of Human Rights', Harvard Human Rights Journal, 21: 7-46 (2008), p. 7.

62 Bellamy, 'The Humanisation of Security?. 
responses continues to vary from case to case, ${ }^{63}$ protection practices have become habitual, and the Security Council has referred to the responsibility to protect principle in countless resolutions and presidential statements. ${ }^{64}$ The protection regime encompasses a repertoire of instruments, including a range of robust measures short of the use of force, including sanctions and diplomacy. Given that coercive measures are more contentious, non-coercive measures are used to fill protection gaps where international actors struggle to agree on, or implement, measures that lack the consent of the state that is struggling to meet its protection responsibilities. Humanitarian actors step in where politics and diplomacy has failed. However, humanitarians also face practical constraints - similar to those of states with the capacity to act - in terms of limits to budgets, lack of access, and uncertainty. ${ }^{65}$

Furthermore, the failure to clearly assign protection duties raises both practical and moral questions. In practical terms, the failure to assign permanent responsibilities inhibits effective coordination by raising transaction costs, potentially duplicating responsibilities, and slowing protective responses. On a case-by-case basis, states and humanitarian relief agencies devise responses to individual crises. Precious resources are wasted, and time is lost, as relevant actors piece together information about crises, and then co-ordinate responses with other relevant actors. Institutionalising protective measures, on the other hand, with clear manuals for action and protocols for case-specific responses, and the assigning of permanent responsibilities among international actors, would permit efficient and rapid protective action across cases, with decisions guided by need and other predetermined criteria alone. For example, states have begun to devise national mechanisms for the prevention of atrocities, which entails monitoring and early warning; training and mainstreaming of best practices; development of policy and recommendations; and co-ordination

63 Labonte, 'Whose Responsibility to Protect?' For an account of the way in which developing human protection norms, within the constructivist paradigm, and material interests, within the rationalist paradigm, interact to produce specific intervention behaviour (here focused on the consistency of armed responses to humanitarian crises by states), see also Luke Glanville, 'Norms, Interests and Humanitarian Intervention', Global Change, Peace \& Security, 18(3): 153-71 (2006).

64 Global Centre for the Responsibility to Protect, 'UN Security Council Resolutions and Presidential Statements Referencing R2P', https://www.globalr2p.org/resources, accessed 8 May 2020.

65 Peter Hoffman and Thomas Weiss, 'Humanitarianism and Practitioners: Social Science Matters', in Michael Barnett and Thomas G. Weiss (eds.), Humanitarianism in Question (Ithaca and London: Cornell University Press, 2018). 
with external bodies. ${ }^{66}$ The development of these national mechanisms, as well as national focal points and, at the international level within the UN, a dedicated Group of Friends, has improved the coherence of the protection regime, but overall, the regime still lacks the coherence that would be required to dramatically improve the consistency of protective action. An impediment to institutionalisation, however, is contestation of the norm that slows the implementation of protection practices at the domestic, regional, and international levels. ${ }^{67}$ Without institutionalisation of the protection principles that underpin the regime, however, it is likely that collective responses are limited to situations in which protective agents are willing to support protective action, or at least not oppose protective responses of other agents. ${ }^{68}$

A failure to assign protection responsibility also raises moral questions. First, while selectivity on the grounds of pragmatism may have been justifiable in the context of the humanitarian intervention debate, the greater variety of protective agents - no longer solely states - as well as the wider repertoire of measures available to them, including non-coercive measures, may undermine the defence of selectivity on the grounds of pragmatism. While it may not have been possible for states with the means and the capacity to 'intervene (militarily) everywhere, all the time', it may well be possible - or, at least, conceivable that a range of international actors, including nonstate actors, could commit to consistent responses, also encompassing non-military and non-coercive means. In other words, while consistent responses are morally necessary, consistent means of responses are not, because cases vary. This does not mean to say, however, that like cases should not be treated alike - if there was sufficient agreement among international actors on procedural rules and best practices, one would expect uniformity of responses for similar cases to eventually take root.

Second, regime incoherence impedes the ability of affected populations to invoke robust protection responses. First, incoherence results in a lack of clarity with regard to rights and responsibilities of protection agents, and of avenues, for individuals and groups in need of protection, for soliciting protective responses from a range of actors, including states, international organisations, and civil society actors, as well as avenues for seeking redress and justice where actors have failed to meet protection responsibilities. Affected populations

66 Samantha Capicotto and Rob Scharf, 'National Mechanisms for the Prevention of Atrocity Crimes', Genocide Studies and Prevention: An International Journal, 11(3): 6-19 (2018).

67 Welsh, 'Norm Contestation and the Responsibility to Protect'; Alan Bloomfield, 'Norm Antipreneurs and Theorising Resistance to Normative Change', Review of International Studies, 42(2): 310-33 (2016).

68 I thank one of the anonymous reviewers for making this point. 
ought to be subjects - not objects - but are disempowered in a self-help system in which there are no institutionalised mechanisms for calling on international actors to respond. The result is a narrative premised on the idea that foreign interveners are 'here to help' 69 - but this help is entirely discretionary, with no corollary right to protection. Not only does this limit the effectiveness of the protection regime - it also serves to normalise unequal power relations between protectors and the protected. In contrast, consistent international responses, by strengthening the protection regime, can contribute to transcend the 'here to help' narrative, by promoting the idea that protection is a duty owed to a protectee, as is the case for the domestic level, where citizens expect domestic law enforcement mechanisms will apply consistently and invariably, and where citizens perceive they are entitled to protection.

Furthermore, when inconsistent responses across cases undermine the perceived legitimacy of protection principles and associated actors and institutions, this may limit the capacity of the law and norms to shape future international responses and help save lives. The fallout from Kosovo and Libya irrespective of the extent to which these interventions were successful in bringing about positive humanitarian outcomes - are examples here. ${ }^{70}$ While the intervention in Kosovo was conducted without an explicit, a priori mandate by the UN Security Council, effectively establishing a precedent for circumvention of Charter stipulations, ${ }^{71}$ NATO's intervention in Libya was unprecedented in that it constituted the first time the Council authorised military intervention, invoking the responsibility to protect, for civilian protection purposes without the consent of the host government. All of the BRIC states - Brazil, Russia, India, and China (as well as Germany) - had abstained from voting on Security Council Resolution 1973, allowing the passage of the resolution. However, BRIC states subsequently criticised the intervention for exceeding the

69 Séverine Autesserre, Peaceland (Cambridge: Cambridge University Press, 2014).

70 Measuring outcomes is complicated, requiring a definition of 'successful outcomes' and the identification of suitable indicators. The analysis must, by definition, be counterfactual. No studies have as yet attempted a systematic study of the outcomes of armed intervention or other international measures. Alan Kuperman discusses alternative outcomes - the numbers of lives that could have potentially been saved - in the case of Rwanda, Kosovo, and Libya. See, for the case of Rwanda, Alan J. Kuperman, The Limits of Humanitarian Intervention: Genocide in Rwanda (Washington, D.C.: Brookings Institution Press, 2001); for the case of Kosovo, Alan J. Kuperman, 'The Moral Hazard of Humanitarian Intervention: Lessons from the Balkans', International Studies Quarterly, 52(1): 49-80 (2008); and for the case of Libya, Alan J. Kuperman, 'A Model Humanitarian Intervention? Reassessing NATO's Libya Campaign', International Security, 38(1): 105-36 (2013).

71 Richard A. Falk, 'Kosovo, World Order, and the Future of International Law', American Journal of International Law, 93(4): 847-57 (1999). 
terms of the mandate by targeting the Libyan government and providing arms to rebel forces. ${ }^{72}$ The case thus illustrates the tension between consistency as compliance (with norms of protection in a particular case), and consistency as invariability (of collective responses across cases).

Empirically, episodes of state-perpetrated mass killing are rarely terminated by third party military intervention - the predominant form of ending is when perpetrators have achieved their goals. ${ }^{73}$ Negotiated settlements are similarly rare. This suggests that across cases, international responses remain characterised by indecisiveness and inaction. A first step towards closing protection gaps may be to increase public awareness of human protection norms and the broader regime. The conceptual groundwork has been accomplished - a critical mass of states and key civil society actors now actively and fully support the principles associated with the protection regime - but beyond the epistemic community engaged with human protection, broadly defined, there is still insufficient lack of knowledge of international human protection principles. The ambiguity of the principles associated with the protection regime has impeded its internalisation among policymakers and institutionalisation at the regional level. ${ }^{74}$ This, in turn, impedes the ability of relevant actors to invoke norms of protection, or to name and shame violators - including international actors with protection duties. Norm localisation at the regional, subregional, and domestic levels may help clarify human protection norms, hence reduce ambiguity, and increase coherence. ${ }^{75}$ This requires greater participation of relevant actors, including the wider international public, and active engagement of a range of stakeholders in the deliberations about changes and reforms required, at all levels, to allow the protection regime to consolidate.

\section{5}

\section{Conclusions}

'Consistency' as an ethical standard provokes a plethora of questions pertaining to law, ethics, and policy. One might ask whether deontological - rules-based approaches are required at all; and if so, which principles best guide prudential

72 Andrew Garwood-Gowers, 'China and the "Responsibility to Protect”: The Implications of the Libyan Intervention', Asian Journal of International Law, 2(2): 375-93 (2012), p. 387.

73 Alex J. Bellamy, 'When States Go Bad: The Termination of State Perpetrated Mass Killing', Journal of Peace Research, 52(5): 565-76 (2015).

74 Chiara De Franco, Christoph O. Meyer, and Karen E. Smith, "Living by Example?" The European Union and the Implementation of the Responsibility to Protect (R2P)', JCMS: Journal of Common Market Studies, 53(5): 994-1009 (2015). tutional Change in Asian Regionalism', International Organization, 58(2): 239-75 (2004). 
judgement; and whether selectivity is defensible, if outcomes are positive. One might ask whether there is norm conflict, and what could be done to reduce it. What counts as legal precedent; and how accountability mechanisms can be improved? One might ask, further, how ambiguity could be reduced, and what it would take to forge an international consensus on norms of protection. Finally, one might ask what could be done to promote protection practices that improve humanitarian outcomes. It is evident - and each of these prisms attests to this - that incoherence continues to characterise the international human protection regime.

This article has argued that coherence is a prerequisite for the consistent application of norms of protection. The exposition of the various meanings of consistency, with illustrations, is value neutral. Yet these definitions and the relationship between consistency as compliance and consistency as invariability also have normative implications. The article has outlined the ways in which the norm conflict between Charter provisions and human rights law creates ambiguity, and provides fertile ground for strategic application of the law, and conduct of foreign policy. Harmonising the existing body of law (the Charter, the statutes of international and regional international criminal courts, and the provisions of IHRL and IHL) would help reduce norm conflict. Equally, further specification of the conditions under which certain provisions apply reduces opportunities for strategic pursuit of political gain through mechanisms of justice.

This is not to say, however, that blind adherence to principles is always the right course of action. Indeed, it is only through autonomy and agency that the protective agent acquires the ability to form prudential judgment based on close consideration of case and context. Furthermore, while lack of coordination among institutions may result in incoherence, a greater number of independent actors may also mean more opportunities for protective responses by actors with both the will and the capacity to act, ${ }^{76}$ which remains imperative if protection objectives are to be realised in an international society where protection norms remain contested and institutionalisation is incomplete. A similar dilemma arises with regard to structure. While a multiplicity of avenues for accountability and redress may provide the accused with an opportunity of escaping justice, ${ }^{77}$ a multiplicity of avenues for pursing accountability may

${ }_{76}$ Lori Fisler Damrosch, 'The Inevitability of Selective Response? Principles to Guide Urgent International Action' in Albrecht Schnabel and Ramesh Thakur (eds.), Kosovo and the Challenge of Humanitarian Intervention: Selective Indignation, Collective Action, and International Citizenship (Tokyo: UNU Press, 200o), http://archive.unu.edu/p\&g/kosovo_full. htm\#25.

77 Matiangai Sirleaf, 'Regionalism, Regime Complexes, and the Crisis in International Criminal Justice', Columbia Journal of Transnational Law, 54(3): 699-778 (2016). 
also provide victims with alternative avenues for pursuing justice, and it may provide more opportunities for any form of accountability mechanisms being implemented, where resources are scarce. Again, the tension between consistency as compliance and consistency as invariability is evident, given that the fragmentation of the protection regime creates indeterminacy and uncertainty, neither of which promote the wider consolidation of the protection regime.

Consequently, it stands to reason that international rights and justice would be served well if, internationally, responsibilities were clearly assigned and principles were more coherent. What is required, therefore, is a coherent normative architecture and clearly articulated, sound policy. The international protection regime remains incoherent; despite efforts to reconceptualise state sovereignty as contingent upon the effective protection of populations in need, sovereignty norms still serve to constrain international responses. International principles require further elaboration on recommendations for best practice and common standards to guide the work of protection agents. At present, the regime remains characterised by norm conflict. However, institutionalisation is required for protection norms to acquire meaning to protective agents and protectees, alike. Reducing the incoherence of the present regime necessitates engagement with the question of how sovereignty norms and human protection norms are reconcilable not just in theory, but also in practice. Security Council reform, as well as the progressive institutionalisation of human rights at the domestic level, may constitute ways forward. ${ }^{78}$ Further elaboration of relevant principles can help to reduce ambiguity, and improve the overall coherence of the regime. Unavoidably, this will mean increased specificity and complexity, but this may be a price worth paying for effective, legitimate protection. ${ }^{79}$

The process of establishing institutions, at the governmental level, is largely state-driven, but in the realm of civil society, non-governmental organisations and think-tanks, as ideational drivers of change, have an important role to play ${ }^{80}$ At the level of policy and diplomacy the establishment of a range of formal and informal mechanisms for regular deliberations on matters of policy and practice is a useful starting point. ${ }^{81}$ For example, guidelines for early warning and streamlined protocols could be implemented at all levels,

78 Adrian Gallagher, 'The Responsibility to Protect Ten Years on from the World Summit: A Call to Manage Expectations', Global Responsibility to Protect, 7(3-4): 254-74 (2015).

79 Reisman, 'Sovereignty and Human Rights in Contemporary International Law'.

80 Richard Price, 'Transnational Civil Society and Advocacy in World Politics', World Politics, 55(4): 579-606 (2003).

81 Bellamy, 'Negotiating the Responsibility to Protect in the UN System'. 
including at the UN, within regional organisations, and by states. This would reduce ambiguity, help to assign responsibilities, and improve coherence. The UN's procedures are fairly elaborate, but at the regional and subregional levels, prevention and protection implementation varies. ${ }^{82}$ These debates ought not to be restricted to narrow epistemic silos, but should be carried to wider audiences, and should seek to engage with the perspectives of the critics.

States and other international actors have a responsibility to protect, but the means for doing so have not been spelt out clearly. There is hardly a crisis in which third parties agree on the best course of action. In the present international context, protective agents are afforded a degree of autonomy and discretion that results in confusion, impedes effective coordination, invites inconsistency and, almost as a matter of routine, opens up the actions of protection agents to the charge of hypocrisy and double standards. Infusing the emergent protection regime with more coherence would greatly improve the prospects of consistent responses, understood both as the adherence to international law and norms of protection, as well as the invariable provision of protection to populations in need. Ultimately, there is no compelling excuse for inconsistency in the practice of human protection. Addressing the incoherence of the regime, I have argued here, is a first step towards realising consistent protection practice.

82 Stanley Foundation, "The Role of Regional and Subregional Arrangements in Strengthening the Responsibility to Protect' (New York: The Stanley Foundation, 2011), www.stanley foundation.org. 